\title{
THE USE OF SUCTION DRAINAGE IN THE OPERATION OF MENISCECTOMY
}

\author{
J. P. BROWETT, A. N. GIBBS, S. A. COPELAND, L. J. DELISS \\ From the Princess Alexandra Hospital, Harlow, Essex
}

\begin{abstract}
A prospective trial has been carried out to determine the value of suction drainage in the operation of meniscectomy. One hundred operations were analysed, in half of which drains had been used. The use of the drain could not be shown to result in any sustained advantages. The demand for analgesics after the operation was reduced but not to a statistically significant level. The size of the early effusion was significantly reduced, but this benefit was lost when the knee was mobilised. The return of power to the quadriceps and of movement to the knee were not hastened. The average volume of fluid drained was 134 millilitres and it has been shown that forty-eight hours is a suitable time for removal of the drain. The use of suction drainage is not advocated for the uncomplicated operation of meniscectomy.
\end{abstract}

Drainage of the knee after meniscectomy was first described by Chandler in 1949. He described closed drainage of the suprapatellar pouch into the substance of the quadriceps. In 1969 Bryan, Dickson and Taylor reported a trial comparing recovery from meniscectomy with and without suction drainage and immobilisation in a cast. They concluded that drainage offered no advantage in recovery of strength and movement. There were, however, many variable factors in their trial.

Closed suction drainage is widely used in orthopaedics. Benefits are obtained where there is a large potential dead space or when increased bleeding is expected, as when medullary bone is divided or large raw areas of tissue are exposed (Waugh and Stinch field 1961). The theory of using suction drainage after operations on the knee is to remove the initial haemarthrosis. The patient benefits from the reduction of the painful distension and removal of blood which may be a synovial irritant with subsequent effusion.

A prospective trial was therefore designed to determine the value of suction drainage after meniscectomy.

\section{METHOD}

Over a period of eighteen months all patients undergoing meniscectomy alone, through a single arthrotomy, were included in the trial. Patients were allocated to drained and undrained groups according to their hospital numbers, and the trial continued until there were fifty patients in each group. All operations were performed on exsanguinated limbs and a tourniquet was always used. The surgeons involved used their own techniques, which differed insignificantly. Drainage tubes were passed up through the medial or lateral synovial recesses and out through the suprapatellar pouch. All wounds were closed in layers with continuous Dexon sutures and the tourniquet was released after the application of a gauze dressing, cotton wool and a crepe bandage. The drainage tubes were connected to Redivac vacuum bottles at a pressure of 600 millimetres of water.

Management after the operation was identical in all cases. Static quadriceps exercises and straight leg raising were encouraged on recovery from the anaesthetic. Analgesics were given on demand; Omnopon by injection initially, then Distalgesic tablets later. All drains were removed forty-eight hours after the operation. The wounds were inspected at ten days after medial meniscectomy and twelve days after lateral meniscectomy. Two extra days were allowed

Table I. Distribution of patients

\begin{tabular}{|l|c|c|}
\hline & Not drained & Drained \\
\hline Female & 14 & 7 \\
Male & 36 & 43 \\
Medial meniscectomy & 31 & 29 \\
Lateral meniscectomy & 19 & 21 \\
Locked knees & 5 & 11 \\
Preliminary arthroscopy & 16 & 12 \\
\hline
\end{tabular}

for healing of the tighter lateral structures. Full weight-bearing and knee flexion were started when the wound had healed and most patients were discharged on the day of wound inspection. The patients attended daily for outpatient physiotherapy and were reviewed three weeks after the operation.

Data were collected to show whether suction drainage had any effect on the demand for analgesics, on the day when straight leg raising was achieved, on the size of the effusion at the time that the wound was inspected and on the day of discharge from the ward. At three weeks, the strength of the quadriceps contraction, the range of

J. P. Browett, M.B., B.S., F.R.C.S., Department of Orthopaedic Surgery, University of the Witwatersrand, New Medical School, Hospital Street, Johannesburg 2001, South Africa.

A. N. Gibbs, B.Sc., M.B., B.S., F.R.C.S., Royal National Orthopaedic Hospital, 234 Great Portland Street, London W1N 6AD, England. S. A. Copeland, M.B., B.S., F.R.C.S., Queen Elizabeth Hospital for Children, Hackney Road, Bethnal Green, London E2 8PS, England. L. J. Deliss, M.B., Ch.B., F.R.C.S., St Bartholomew's Hospital, West Smithfield, London EC1 7BE, England.

Requests for reprints should be sent to Mr J. P. Browett. 
knee movement and, again, the size of the effusion were recorded. The size of effusion was assessed clinically and classed as small if the sign of emptying of the lateral recesses was present, moderate when the patellar tap test was positive and tense if the effusion was under pressure. The date of the return to work and sport was subsequently recorded.

In order to determine the proportion of blood in the drainage fluid five volunteer patients were studied using a dilution technique with red cells labelled with chromium-51. The labelled cells were administered by intravenous injection at the time of induction of the anaesthetic. Blood samples and drainage fluid were collected at two, twenty-four and forty-eight hours after the operation.

\section{RESULTS}

One hundred operations were analysed, in half of which drains had been used. The drained and non-drained groups were well matched before operation for the duration of symptoms and the presence of an effusion and of wasting of the quadriceps. The average age of the

Table II. Major element of morbid anatomy in menisci removed

\begin{tabular}{|l|c|c|}
\hline & Not drained & Drained \\
\hline Tears & 34 & 39 \\
Cysts & 9 & 2 \\
Degenerations & 4 & 4 \\
Normal & 3 & 3 \\
Discoid & 0 & 2 \\
\hline
\end{tabular}

non-drained group was thirty-four years and that of the drained group was thirty-three years. The distribution of patients within the groups is shown in Table I. The morbid anatomy of the excised menisci in the two groups is recorded in Table II, and Table III illustrates other abnormalities found at operation.

After the operation, there was no difference between the groups for the time taken to achieve a straight leg raise (Table IV). Only one wound was not fully healed on the day of inspection and this knee had

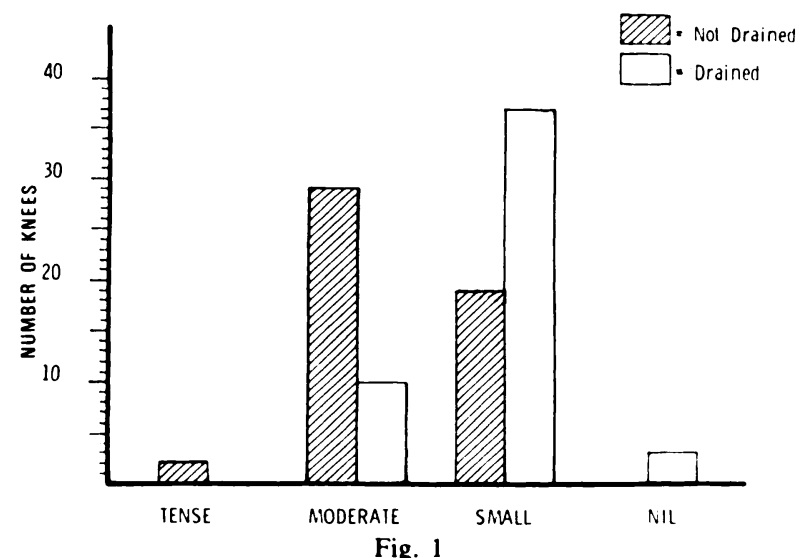

Size of effusion at the time of wound inspection.
Table III. Other significant abnormalities

\begin{tabular}{|l|c|l|c|}
\hline & Not drained & & Drained \\
\hline $\begin{array}{l}\text { Tibiofemoral } \\
\text { degeneration }\end{array}$ & 12 & & 10 \\
$\begin{array}{l}\text { Patellofemoral } \\
\text { degeneration }\end{array}$ & 2 & & 4 \\
Loose body & 2 & & 1 \\
$\begin{array}{l}\text { Instability (marked) } \\
\text { Inflamed fat pad }\end{array}$ & 1 & Fibrotic nodule & 1 \\
$\begin{array}{l}\text { Adhesion bands } \\
\text { Anterior cruciate tear } \\
\text { (acute) } \\
\text { Total }\end{array}$ & 1 & Synovitis & 1 \\
$(17$ knees) & 20 & Cartilage mass & 1 \\
\hline
\end{tabular}

Table IV. Straight leg raising

\begin{tabular}{|c|c|c|}
\hline & Not drained & Drained \\
\hline 48 hours & 17 & 21 \\
2-5 days & 28 & 24 \\
5-14 days & 5 & 5 \\
\hline
\end{tabular}

Table V. Demand for analgesic

\begin{tabular}{|c|c|c|}
\hline & Not drained & Drained \\
\hline $\begin{array}{l}\text { Average number of } \\
\text { parenteral injections } \\
\text { (range } 0-3 \text { ) }\end{array}$ & 1.6 & 1.3 \\
\hline $\begin{array}{l}\text { Average number of } \\
\text { administrations of } \\
\text { oral analgesics }\end{array}$ & $\begin{array}{c}13.8 \\
\text { (S.D. }=8.16)\end{array}$ & $\begin{array}{c}11.1 \\
(S . D .=7.01)\end{array}$ \\
\hline $\begin{array}{l}\text { Average number of } \\
\text { days for which } \\
\text { oral analgesics } \\
\text { were given }\end{array}$ & $\begin{array}{c}5.6 \\
\text { (S.D. }=3.23)\end{array}$ & $\begin{array}{c}4.8 \\
(S . D .=2.45)\end{array}$ \\
\hline
\end{tabular}

S.D. $=$ Standard Deviation

not been drained. At the time of wound inspection, knees that had been drained were found to have smaller effusions. Three patients in this group had no effusion and there were no tense effusions (Fig 1). The difference between the groups was statistically significant $(P=<0.01)$. Drainage could not be shown to reduce the time spent in hospital, but three patients in the non-drained group remained in hospital until the fourteenth day, one with a tense effusion. The demand for parenteral and oral analgesics was reduced by the use of suction drainage (Table V). These differences could not be shown to have statistical significance due to the small number of parenteral injections and the wide variation of requirements for oral analgesics. Patients undergoing arthroscopy as a preliminary procedure 
J. P. BROWETT, A. N. GIBBS,

appeared to require more analgesics, but their limited numbers precluded further analysis.

Three weeks after operation, no differences between the groups were recorded for power of the quadriceps or the range of movement in the knee (Tables VI and VII). At this time, the initial reduction in

Table VI. Power of quadriceps contraction three weeks after operation

\begin{tabular}{|l|c|c|}
\hline & Not drained & Drained \\
\hline Good & 24 & 27 \\
Fair & 15 & 15 \\
Poor & 8 & 8 \\
No follow-up & 3 & 0 \\
\hline
\end{tabular}

Table VII. Knee movement three weeks after operation

\begin{tabular}{|l|c|c|}
\hline & Not drained & Drained \\
\hline Extension lag & 3 & 3 \\
\hline Full & 13 & 18 \\
Limited & 23 & 23 \\
Stiff $\left(<100^{\circ}\right)$ & 11 & 9 \\
No follow-up & 3 & 0 \\
\hline
\end{tabular}

size of the knee effusions in the drained group was found to be completely lost (Fig. 2). Moreover, subsequent follow-up indicated that the time taken for complete reabsorption of the effusion was the same.

The postal inquiry produced sixty-two replies. The non-drained group returned to work and sport an average of four and eleven weeks after operation respectively, while the drained group returned at four and a half and nine weeks.

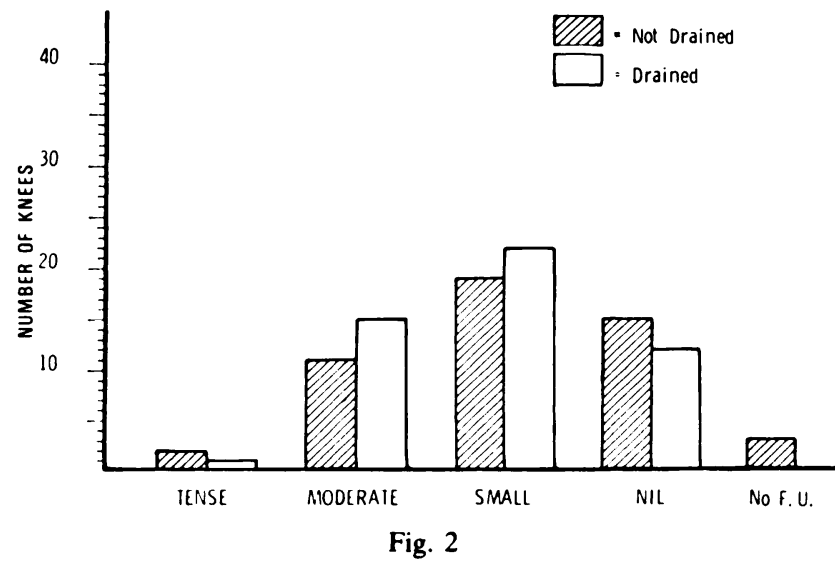

Size of effusion three weeks after operation.
Two complications occurred that could be attributed to the drains. One knee rapidly drained 350 millilitres of blood and, as it was felt that the drain was perpetuating the haemorrhage, the drainage tube was temporarily clamped off. The clamp was later released to drain a further 150 millilitres. In another patient the drain could not be removed at forty-eight hours and attempts to do so resulted in the drain breaking within the joint. A further arthrotomy was necessary to remove the broken portion of drain which was found to be trapped between the joint surfaces.

\section{Further study on the drainage fluid}

The volume of fluid drained from each knee was recorded and ranged from 40 to 500 millilitres with an average of 134 millilitres. Nearly all the blood had been removed by forty-eight hours (Fig. 3). The volume of drainage did not fall at the same rate in all cases. The average volume drained from knees with pre-existing degenerative change was 159 millilitres and that from knees without such change was 116 millilitres.

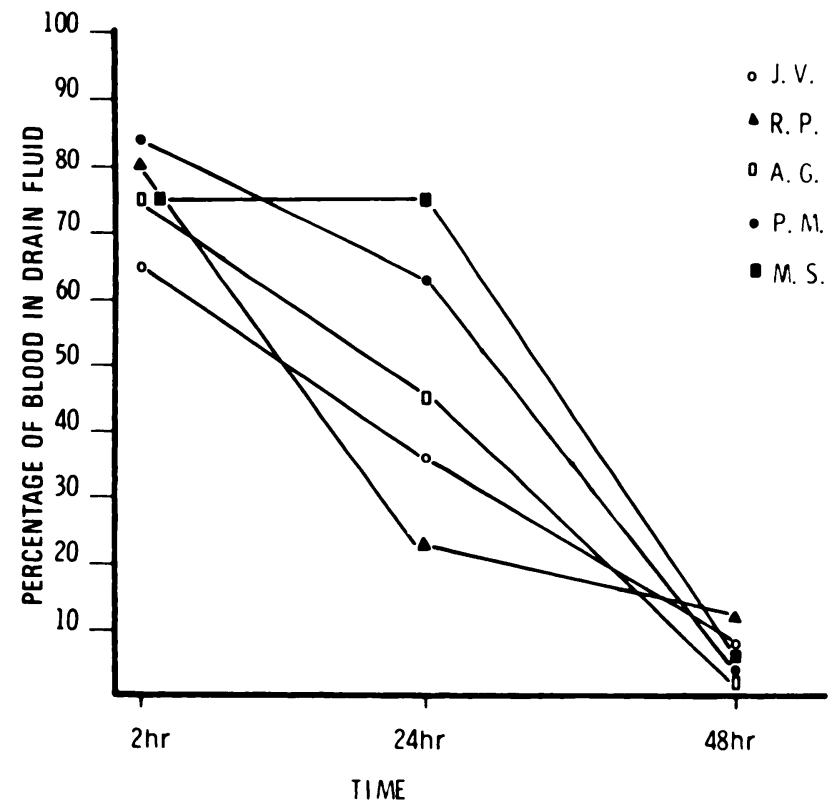

Fig. 3

Study of red cells labelled with chromium-51.

\section{DISCUSSION}

These results show that the use of suction drainage has no sustained advantage for the patient undergoing a routine meniscectomy. The demonstrated reduction in size of the early effusion was not maintained after mobilisation. This transitory effect of drainage was the impression gained by Bryan, Dickson and Taylor (1969). It would appear from our results that the cause of the late effusion is not the presence of a haemarthrosis but the surgical trauma of meniscectomy. The increase in the size of the effusion in the drained group after 
mobilisation may well be related to their physiotherapy, as evidenced by the fact that 36 per cent of these patients regained full flexion within three weeks. Indeed, during this time some patients developed patellofemoral symptoms. The knee classes attended by these patients were intensive and associated with a sense of competition. More gentle attempts at regaining flexion over a longer period might well avoid such problems. There were, however, no tense persisting effusions in the drained group and the drains may be effective in reducing this occasional complication. Our failure to show early relief of pain in the drained group suggests that the surgical incision, rather than the haemarthrosis, is the major cause of pain following meniscectomy. Some patients actually expressed discomfort due to the presence of the drain. With removal of the drain, often a very painful procedure, their discomfort was relieved. Like Bryan, Dickson and Taylor we have found no improvement in the power of the quadriceps contraction or in the speed of recovery of the knee flexion. Furthermore, the times for complete reabsorption of the effusions have not been influenced by drainage. Certainly the use of the drain did not hasten the patient's return to work and sport.

Careful positioning of the drain and closing the wound with the knee extended should avoid the complication of entrapment. Although the drain appeared to perpetuate the bleeding in the other complicated case, it also salvaged the situation by draining a further 150 millilitres, resulting in a moderate effusion at ten days and a small effusion at three weeks.

The study of red cells labelled with chromium-51 demonstrated that forty-eight hours after operation an average of only 8 per cent blood is present in the drainage fluid, indicating that this is a suitable time to remove the drain. Parallel studies using haematocrit, haemoglobin and red cell count were performed and correlated well providing there were no blood clots or haemolysis in the fluid. In the chromium technique, red cells and clots are lysed before the count is performed, and haemolysis due to time is irrelevant as the chromium stays in the sample.

We have shown in this trial that suction drainage reduces the size of the early effusion following meniscectomy, but that this benefit is lost after mobilisation. We believe that suction drainage may well be indicated if increased bleeding is expected, where more extensive procedures have been performed or where posterior capsular dissection has been difficult. The use of a drain is associated with a small morbidity and we feel that in the routine operation of meniscectomy it is unnecessary.

We would like to sincerely thank Mr G. R. Fisk, Mr H. Poirier and Mr J. Read for allowing this trial to be carried out on their patients and for their advice and encouragement. We also thank Mr Brian Newland for his work with the ${ }^{\text {si }} \mathrm{Cr}$-labelled red cell study.

\section{REFERENCES}

Bryan, R. S., Dickson, J. H., and Taylor, W. F. (1969) Recovery of the knee following meniscectomy. Journal of Bone and Joint Surgery, 51-A, 973-978.

Chandler, F. A. (1949) Closed drainage of the knee joint following arthrotomy. Journal of Bone and Joint Surgery, 31-A, 580-581.

Waugh, T. R., and Stinchfield, F. E. (1961) Suction drainage in orthopaedic wounds. Journal of Bone and Joint Surgery, 43-A, 939-946. 